\title{
VIÑAS Y ÁRBOLES FRUTALES EN EL REGISTRO ETNOHISTÓRICO DEL NOROESTE ARGENTINO: APUNTES PARA LA INVESTIGACIÓN ARQUEOLÓGICA
}

\author{
VINES AND FRUIT TREES IN THE ETHNOHISTORICAL RECORD OF THE \\ ARGENTINE NORTHWEST: NOTES FOR ARCHAEOLOGICAL RESEARCH
}

\author{
Vanina Castillón $n^{1,2}$
}

\begin{abstract}
A partir de la lectura de documentos escritos en los siglos XVI y XVII, se analizaron en este caso únicamente las menciones a un grupo de especies introducidas: viñas y árboles frutales. Se relevaron las etnoespecies de interés y se infirieron las especies taxonómicas, en relación a cuatro ciudades fundadas en el siglo XVI: Santiago del Estero (en Santiago del Estero), Londres de La Nueva Inglaterra (en Catamarca), San Miguel de Tucumán (en Tucumán) y Nuestra Señora de Talavera (en Salta). Se estableció que las viñas y árboles frutales habrían sido introducidos tempranamente y cultivados principalmente en las chacras de las ciudades. Además, se registró la emergencia de nuevos actores vinculados a las prácticas agrícolas, así como menciones a la experimentación, al almacenamiento y la comercialización. Finalmente, se propusieron indicadores arqueológicos sobre la presencia de estas especies en las ciudades coloniales tempranas del NOA.
\end{abstract}

Palabras claves: viñas, árboles frutales, ciudades coloniales, Noroeste argentino.

Based on the reading of documents written in the 16th and 17th centuries, an analysis is presented focusing only on the mentions of a group of introduced species: vines and fruit trees. The ethnospecies of interest were highlighted, and taxonomic species were inferred in relation to four cities founded in the 16th century: Santiago del Estero (in Santiago del Estero), Londres de la Nueva Inglaterra (in Catamarca), San Miguel de Tucumán (in Tucumán), and Nuestra Señora de Talavera (in Salta). It was established that the vines and fruit trees would have been introduced in an early period and cultivated mainly in the orchards of the cities. Furthermore, new actors linked to agricultural practices were identified, and mentions of experimentation, storage, and commercialization were recognized. Finally, archaeological indicators were proposed for the presence of these species in the early colonial cities of Argentine Northwest.

Key words: Vines, fruit trees, colonial cities, Argentine Northwest.

El presente artículo forma parte de unainvestigación doctoral en la cual se indaga, por medio del análisis del registro escrito y arqueológico, el uso y circulación de las plantas en contextos urbanos del periodo Colonial en el Noroeste argentino (NOA) (Castillón et al 2019). Esta región estaría comprendida dentro de lo que fue denominada administrativamente como Gobernación del Tucumán al momento de su creación (año 1563) y dependió políticamente del Virreinato de Perú (Gentile 2012). Allí se establecieron un conjunto de ciudades interconectadas que afianzaron la ocupación ibérica en el territorio. Hasta el momento, la ubicación inicial de cuatro de las instalaciones urbanas fundadas durante el siglo XVI ha sido identificada arqueológicamente en el NOA (Igareta 2019): Santiago del Estero (1553) en el sitio Parque Aguirre en la provincia de Santiago del Estero; Londres de la Nueva Inglaterra (1558) en el sitio arqueológico El Shincal en la provincia de Catamarca; San Miguel de Tucumán (1565) en el sitio Ibatín en Tucumán; Nuestra Señora de Talavera (1566) en el sitio Esteco I en Salta (Figura 1). A excepción de la primera, las otras tres ciudades fueron trasladadas desde la mencionada ubicación inicial a otros emplazamientos a los pocos años de su fundación. El caso más emblemático fue el de Londres de la Nueva Inglaterra, cuya primer fundación duró apenas cuatro años y luego fue trasladada seis veces durante los siglos XVI y XVII (Ardissone 1961).

\footnotetext{
${ }^{1}$ Consejo Nacional de Investigaciones Científicas y Técnicas (CONICET), Buenos Aires, Argentina.

2 División Arqueología, Facultad de Ciencias Naturales y Museo, Universidad Nacional de La Plata. La Plata, Argentina. vaninacastillon@fcnym.unlp.edu.ar
} 


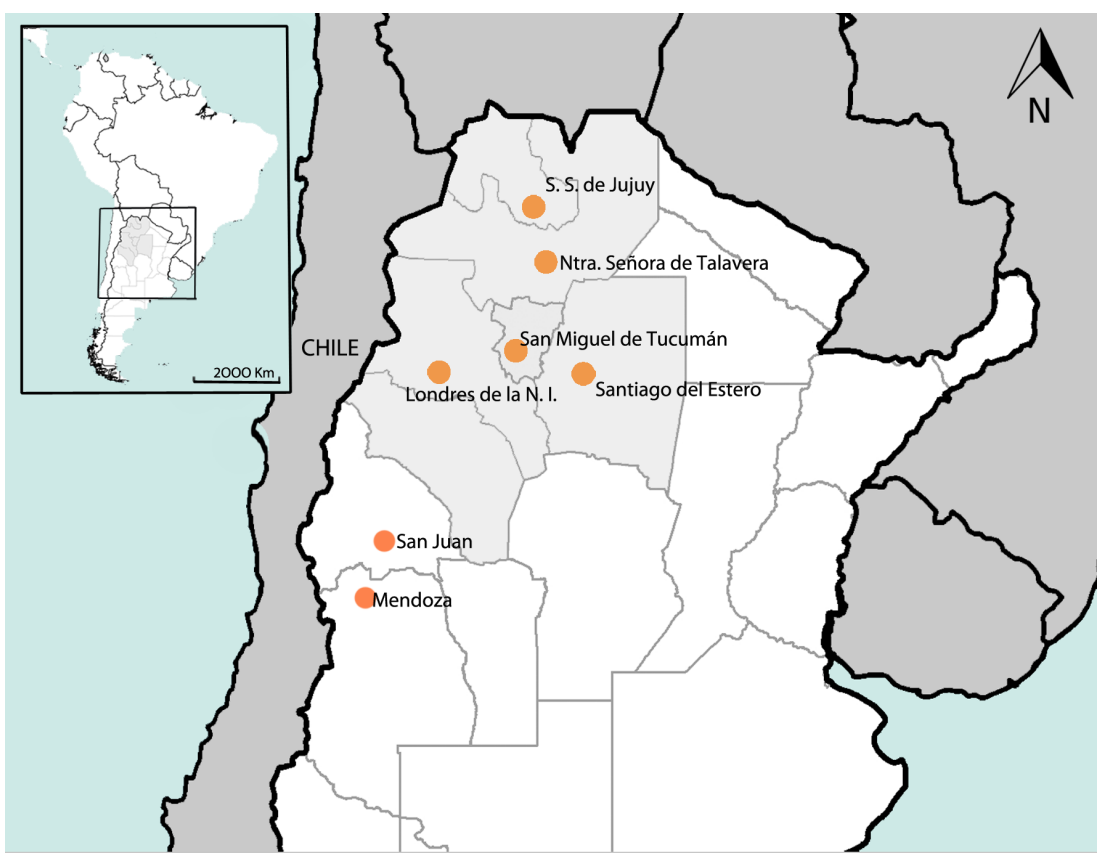

Figura 1. Ubicación de las ciudades mencionadas en este trabajo. El área sombreada corresponde a las actuales provincias del NOA que formaron parte de la Gobernación del Tucumán en el siglo XVI. Fuente: Igareta (2019).

Location of the cities mentioned in this work. The shaded area corresponds to Argentine Northwest provinces, which were part of the Gobernación del Tucumán in the 16th century. Source: Igareta (2019).

En relación a los antecedentes que fueron recopilados para el NOA sobre uso y circulación de plantas en contextos urbanos, en términos generales, salvo contadas excepciones, se abordaron las especies vegetales centrando la atención en ciudades particulares. Es por ello que el presente análisis pretende brindar un panorama comparativo (entre las cuatro ciudades antes mencionadas) y general del NOA dentro de la Gobernación de Tucumán, por medio de la información obtenida de fuentes documentales tempranas producidas en los siglos XVI y XVII. Debido a la extensión que dicha tarea implica, se analizará en este caso únicamente las menciones a un grupo de especies leñosas introducidas: viñas y árboles frutales. Asimismo, se espera generar indicadores arqueológicos que sumen a los ya existentes sobre la presencia de especies vegetales en las ciudades coloniales tempranas del NOA.

\section{Antecedentes Etnohistóricos y Arqueobotánicos}

En este apartado se revisan brevemente algunas de las investigaciones que abordaron específicamente el rol de las plantas en el NOA durante el periodo Colonial, las cuales se resumen en la Tabla 1; sus resultados dieron cuenta de la reconfiguración cultural de las plantas nativas en el sistema colonial así como del impacto de las introducidas en las sociedades indígenas. Las referencias a las plantas se realizan según su nombre vernacular, solo se incluye su identificación taxonómica en la Tabla 1 en los casos en que esta haya sido expresamente propuesta por los autores de los trabajos.

En la jurisdicción de San Salvador de Jujuy, Sica (2005) planteó que la entrada de especies europeas se habría dado de manera anticipada a la fundación de la ciudad y de la mano de los grupos indígenas, y que muchas de las plantas antes cultivadas -maíz, zapallo, poroto y ají- tuvieron que ceder lugar a los nuevos cultivos -trigo, cebada, árboles frutales y videsLa investigación de Lambaré (2015) en Quebrada de Humahuaca (Jujuy), aportó a la historia de la introducción y al reconocimiento de la continuidad del cultivo de variedades de duraznos presentes en la región desde el siglo XVI hasta la actualidad y que forman parte de la identidad local de los lugareños.

En Salta, en el sitio Esteco I, lugar de fundación de Nuestra Señora de Talavera, se recuperó material vegetal herbáceo, restos de cordelería y fragmentos de marlos o tusas ${ }^{1}$ de maíz carbonizados (Marschoff et al. 2014) que aportaron significativamente al estudio de la estratigrafía del sitio. Los trabajos etnohistóricos, por su parte, contribuyeron a caracterizar la ciudad y la heterogeneidad de sus pobladores (Porterie y Simioli 2018; Simioli et al. 2017) y a proponer una historia dinámica del lugar. Los relatos iniciales del siglo XVI dieron cuenta de una ciudad próspera, con abundancia de comidas, cereales, legumbres, viñas y algodonales, desde la cual se exportaban colorantes naturales, textiles 
Tabla 1. Principales antecedentes de plantas en el registro etnohistórico y arqueobotánico de áreas con ocupación urbana del periodo Colonial (fuentes secundarias).

Main information about plants in the ethnohistorical and archeobotanical record of areas with urban occupation of the Colonial period (secondary sources).

\begin{tabular}{|c|c|c|c|}
\hline Área de estudio & Siglos & Autor/es & Principales evidencias etnohistóricas y arqueobotánicas \\
\hline \multirow[t]{2}{*}{$\begin{array}{l}\text { Jujuy y su } \\
\text { jurisdicción }\end{array}$} & XVI-XVII & Sica (2005) & $\begin{array}{l}\text { Ingreso temprano de especies europeas por parte de grupos indígenas, previo a la } \\
\text { fundación de la ciudad. } \\
\text { Plantas nativas- maíz, zapallo, poroto y ají- ceden lugar a los nuevos cultivos -trigo, } \\
\text { cebada, árboles frutales y vides. }\end{array}$ \\
\hline & $\begin{array}{l}\text { XVI - } \\
\text { actualidad }\end{array}$ & Lambaré (2015) & $\begin{array}{l}\text { Continuidad del cultivo de duraznos (Prunus persica) desde el siglo XVI hasta la } \\
\text { actualidad. }\end{array}$ \\
\hline \multirow{2}{*}{$\begin{array}{l}\text { Nuestra Señora } \\
\text { de Talavera }\end{array}$} & \multirow{2}{*}{ XVI-XVII } & Marschoff (2018) & $\begin{array}{l}\text { Abundancia de comidas, cereales, legumbres, viñas y algodonales. Exportación de } \\
\text { colorantes naturales, textiles y miel al Perú. } \\
\text { Transición de actividades productivas agrícolas a ganaderas. }\end{array}$ \\
\hline & & Marschoff et al. (2014) & $\begin{array}{l}\text { Registro arqueobotánico y contexto de hallazgo: } \\
\text { Material vegetal herbáceo, restos de cordelería y fragmentos de tusas de maíz } \\
\text { carbonizados. En: contexto doméstico de descarte o fogón en sitio urbano. }\end{array}$ \\
\hline \multirow[b]{2}{*}{$\begin{array}{l}\text { San Miguel de } \\
\text { Tucumán }\end{array}$} & \multirow[b]{2}{*}{ XVI -XVII } & Noli $(1998,1999,2001)$ & $\begin{array}{l}\text { Preponderancia en la recolección de algarroba (Prosopis spp.). } \\
\text { Uso maderero del lapacho (Tabebuia impetiginosa [sic]), nogal (Juglans australis), } \\
\text { cedro (Cedrella lilloi [sic]), lanza amarilla (Terminalia triflora). }\end{array}$ \\
\hline & & Borsella y Aguirre (2018) & $\begin{array}{l}\text { Relevamiento documental de especies nativas: cebil (Anadenanthera columbrina } \\
\text { [sic]), nogal (Juglans australis), cedro (Cedrela sp.), algarrobales (Prosopis sp), tipa } \\
\text { (Tipuana tipu), maíz (Zea mays), añil (Indigofera tinctoria) y algodón (Gossypium sp.) } \\
\text { y exóticas: trigo (Triticum estivum [sic]), cebada (Hordeum vulgare), legumbres, uva } \\
\text { (Vitis vinifera), naranjo (Citrus sinensis) y durazno (Prunus persica). }\end{array}$ \\
\hline $\begin{array}{l}\text { Santiago del } \\
\text { Estero }\end{array}$ & XVI-XIX & Farberman (2006) & $\begin{array}{l}\text { Incorporación temprana de los productos de la recolección de miel, cera, grana y } \\
\text { algarroba al mercado colonial. }\end{array}$ \\
\hline \multirow[b]{2}{*}{ El Shincal } & \multirow[b]{2}{*}{ XVI-XVII } & \multirow[b]{2}{*}{$\begin{array}{l}\text { Capparelli et al.(2005); } \\
\text { Giovannetti (2005); Lema } \\
\text { y Capparelli (2007), } \\
\text { Capparelli (2009) }\end{array}$} & $\begin{array}{l}\text { Ingreso inicial de cultivos europeos desde Chile a Santiago del Estero. } \\
\text { Circulación y manipulación indígena de cultivos europeos en contextos rituales. } \\
\text { Discusión de la procedencia del algodón (Gossypium sp.). }\end{array}$ \\
\hline & & & $\begin{array}{l}\text { Registro arqueobotánico y contexto de hallazgo: } \\
\text { Carporrestos carbonizados de cebada (Hordeum vulgare), trigo (Triticum aestivum/ } \\
\text { compactum), durazno (Prunus persica), algarrobo (Prosopis spp.), chañar (Geoffroea } \\
\text { decorticans), mistol (Zizyphus mistol), pocoto (Solanum elaegnifolium), maíz (Zea } \\
\text { mays), poroto (Phaseolus lunatus y P. vulgaris), zapallo (Cucurbita sp.), algodón } \\
\text { (Gossypium sp.) y restos de junco (Scirpus sp.) y de preparación a base de ají y poroto. } \\
\text { En: contexto ritual en sitio incaico con ocupación colonial. }\end{array}$ \\
\hline $\begin{array}{l}\text { Gobernación } \\
\text { del Tucumán }\end{array}$ & XVI- XVII & Gentile $(2008,2009)$ & $\begin{array}{l}\text { Relevamiento documental de menciones de cultivo de coca (Erythroxylon coca [sic]) y } \\
\text { cabuya (Fourcroya andina }[\mathrm{sic}] \text { y F. occidentalis [sic]). }\end{array}$ \\
\hline \multirow{3}{*}{ Mendoza } & \multirow{3}{*}{ XVI -XVII } & \multirow{3}{*}{$\begin{array}{l}\text { Chiavazza y Mafferra } \\
(2007) \text {; } \\
\text { Mafferra }(2011,2015 \text {, } \\
2018)\end{array}$} & $\begin{array}{l}\text { Ingreso temprano de cultivos europeos desde Chile por los grupos indígenas previo a } \\
\text { la fundación de la ciudad. } \\
\text { Uso temprano de leña de los árboles frutales introducidos dando cuenta de una amplia } \\
\text { funcionalidad. }\end{array}$ \\
\hline & & & $\begin{array}{l}\text { Registro arqueobotánico y contexto de hallazgo: } \\
\text { Carporrestos carbonizados de trigo (Triticum sp.), cebada (Hordeum sp.), centeno } \\
\text { (Secale sp.), avena (Avena sp.), olivo (Olea } \text { sp.), durazno (Prunus sp.), vid (Vitis sp.) y } \\
\text { algarrobo (Prosopis sp.), chañar (Geoffroea sp.) }\end{array}$ \\
\hline & & & $\begin{array}{l}\text { Antracorrestos correspondientes a duraznero (Prunus aff. persica), membrillero, } \\
\text { manzano o peral (aff. Cydonia/Malus/Pyrus), vid (Vitis vinifera) y tamarindo (Tamarix } \\
\text { gallica) y de especies nativas principalmente Larrea sp., aff. Acacia/Prosopis, } \\
\text { Geoffroea decorticans, aff. Caesalpinia gilliesii, Bulnesia retama, aff. Acacia aroma/ } \\
\text { gilliesii y aff. Prosopis flexuosa. } \\
\text { En: contexto doméstico de descarte en sitio urbano. }\end{array}$ \\
\hline $\begin{array}{l}\text { Chile, Mendoza } \\
\text { y San Juan }\end{array}$ & XVI-XIX & Lacoste et al. (2011) & $\begin{array}{l}\text { Evidencia de desarrollo de fruticultura principalmente vinculada a durazneros, } \\
\text { manzanos, perales, almendros, olivos e higueras. }\end{array}$ \\
\hline
\end{tabular}

y miel al Perú. En cambio, a partir del siglo XVII, los escritos destacan la ocurrencia de pestes, hambrunas, la mortandad indígena, las dificultades en la producción agrícola y en el mantenimiento de las acequias y edificios. Para este periodo, las actividades productivas se habrían orientado a la ganadería. Esta serie de factores confluyeron a que los vecinos soliciten trasladarla a un nuevo emplazamiento (Marschoff 2018).

Para la primera ciudad de San Miguel de Tucumán, se destacan los análisis de Noli quien planteó que, debido 
a la introducción del ganado, las sociedades indígenas redujeron el consumo de maíz, a la vez que fue ganando mayor preponderancia la recolección de algarroba (Noli 1998, 1999). Asimismo, las maderas nativas del piedemonte tucumano -extraídas del lapacho, nogal, cedro, lanza amarilla- fueron objeto de explotación proveyendo materia prima para la construcción y para la confección de carretas. Estas actividades sirvieron de vehículo para la "occidentalización" de los grupos nativos (Noli 2001). El trabajo de Borsella y Aguirre (2018), por su parte, registró los recursos vegetales y animales disponibles en Tucumán a través del análisis de fuentes inéditas del Archivo Histórico de Tucumán. El listado de especies vegetales relevadas incluye entre las nativas: cebil, nogal, cedro, algarrobales, tipa, maíz, añil y algodón, y entre las exóticas: trigo, cebada, legumbres, uva, naranjo y durazno. Además registraron menciones vinculadas a la explotación maderera del cedro y el nogal, así como también pedidos de tierras para establecer áreas de cultivos y de ganadería, dando cuenta de las transformaciones que generaron estas actividades en el ambiente circundante.

Judith Farberman (2006) estudió la recolección de miel, cera, grana ${ }^{2}$ y algarroba en Santiago del Estero desdelaconquistahastafines del siglo XIX, identificando la incorporación temprana de estos productos al sistema de encomiendas. El mercado colonial generó una sobreexplotación de estos recursos, principalmente de la algarroba, que en periodos de extrema sequía era el único fruto silvestre en abundancia, por lo que las vainas recibían la denominación de "frutos del hambre".

En el sitio El Shincal, provincia de Catamarca, el hallazgo de restos de cultivos europeos tales como cebada, trigo y durazno en contexto ritual y datado a mediados del siglo XVII, obligó a un replanteo de las hipótesis sobre su uso y manipulación por parte de las poblaciones indígenas (Capparelli et al. 2005; Giovanetti 2005; Giovanetti y Lema 2005; Lema y Capparelli 2007). Inicialmente se consideraba que los primeros especímenes de plantas europeas habían ingresado al NOA con los grupos colonizadores provenientes del Perú durante la fundación de El Barco (1550) y que prontamente habían sido incorporadas a la dieta indígena (Báez 1947). Sin embargo, los estudios realizados por Capparelli et al. (2005) postularon, mediante la evidencia etnohistórica, que su ingreso había ocurrido desde Chile durante la fundación de Santiago del Estero (1553), a la vez que los resultados del análisis arqueológico cuestionaron la idea de su inmediata incorporación a la alimentación indígena, ya que únicamente fueron recuperados en contexto ritual.El registro arqueobotánico de este sitio comprende además restos de algarrobo, chañar, mistol, junco, pocoto, maíz, poroto y zapallo, restos de una preparación a base de ají y poroto y, además, semillas de algodón (Capparelli
2009). La procedencia de este último en la región aún es discutida (Lema y Capparelli 2007; López Campeny y Taboada 2016).

A diferencia de los trabajos centrados en un sitio/ciudad, Gentile (2008) contempló una escala más amplia de estudio, analizando las menciones al cultivo de coca en la Gobernación del Tucumán y la presencia de tres recursos locales de importancia para la explotación europea: pez (betún o brea natural), hierro y cabuya. Esta última se utilizaría para la confección de cordelería y vestimenta, y en el mantenimiento de navíos españoles (Gentile 2009).

Por último, aunque fuera del área de análisis delimitada pero en relación con lo propuesto en este trabajo, cabe mencionar las investigaciones realizadas en el sitio fundacional de la ciudad de Mendoza, en la que se recuperaron restos de cultivos europeos de trigo, cebada, centeno, avena, olivo, durazno, vid, y restos de especies nativas correspondientes al algarrobo y chañar (Mafferra 2011). Chiavazza y Mafferra (2007) postularon que los huarpes habrían introducido los cultivos europeos desde Chile, previo al ingreso efectivo de los colonizadores a la región cuyana. Además, estudios antracológicos dieron cuenta del uso temprano como leña de la madera del duraznero, de alguna especie de pomácea, de vid y de tamarindo, ampliando la funcionalidad vinculada principalmente con sus frutos (Mafferra 2015, 2018). En vinculación con esta región, los estudios de Lacoste et al. (2011) realizados para Chile, Mendoza y San Juan aportaron al registro del desarrollo de la fruticultura durante el periodo Colonial, especialmente vinculada a los durazneros, manzanos, perales, almendros, olivos e higueras.

\section{Materiales y Métodos}

Los documentos escritos durante el periodo Colonial Temprano que se refieren al NOA son escasos en relación a la producción disponible para otras regiones del continente americano (Gentile 2005). De igual modo, tampoco se dispone de escritos que hayan profundizado en la descripción de las plantas presentes en la región, tales como los realizados por los jesuitas Bernabé Cobo (1890 [1652]) y Joseph de Acosta (2008 [1590]) para el Virreinato del Perú y de Nueva España. Sin embargo, estas obras contienen mínimas referencias al Tucumán, por lo que se las consideró como fuentes de información para la caracterización de las múltiples aplicaciones de las plantas nativas e introducidas en el continente. En el presente trabajo específicamente se analizó un conjunto de documentos éditos que fueron escritos entre los siglos XVI y XVII por individuos que dijeron haber vivido o haber estado de paso por las ciudades del NOA. Las fuentes primarias consultadas se presentan en orden cronológico en la Tabla 2. 
Tabla 2. Fuentes primarias consultadas.

Primary sources consulted.

\begin{tabular}{|c|c|c|c|}
\hline Tipo de documento, autor y contexto & Fecha & Área geográfica & Referencias \\
\hline & Siglo XVI & & \\
\hline $\begin{array}{l}\text { Cartas, ordenanzas, reales cédulas, } \\
\text { informaciones escritas por gobernadores del } \\
\text { Tucumán y por el virrey del Perú. }\end{array}$ & $1553-1600$ & NOA & $\begin{array}{l}\text { Gobernación del Tucumán. Papeles de Gobernadores en el Siglo XVI } \\
\text { (Levillier 1920). } \\
\text { [1] }\end{array}$ \\
\hline $\begin{array}{l}\text { Probanzas, memoriales e informaciones de } \\
\text { conquistadores del Tucumán. }\end{array}$ & $1556-1600$ & NOA & $\begin{array}{l}\text { Gobernación del Tucumán. Probanzas de Méritos y Servicios del Tucumán } \\
\text { (Levillier 1919). } \\
\text { [2] }\end{array}$ \\
\hline $\begin{array}{l}\text { Cartas, pleitos, informaciones, memoriales } \\
\text { presentados en la corte por los procuradores, } \\
\text { apoderados y enviados de las ciudades. }\end{array}$ & $1560-1600$ & NOA & $\begin{array}{l}\text { Gobernación del Tucumán. Correspondencia de los Cabildos en el Siglo XVI } \\
\text { (Levillier 1918). } \\
\text { [3] }\end{array}$ \\
\hline $\begin{array}{l}\text { Crónica escrita por Gerónimo de Bibar } \\
\text { (soldado) que acompañó a Valdivia en su } \\
\text { ingreso a Chile. }\end{array}$ & 1558 & $\begin{array}{l}\text { Chile y } \\
\text { referencias al } \\
\text { NOA }\end{array}$ & $\begin{array}{l}\text { Crónica y Relación Copiosa y Verdadera de los Reynos de Chile (Bibar } 1966 \\
[1558]) \text {. } \\
{[4]}\end{array}$ \\
\hline $\begin{array}{l}\text { Carta de Juan de Matienzo (oidor de } \\
\text { Charcas) al Rey. }\end{array}$ & 1566 & NOA & \\
\hline $\begin{array}{l}\text { Relación geográfica de Diego Pacheco } \\
\text { (gobernador) }\end{array}$ & ca. 1570 & NOA & $\begin{array}{l}\text { Relaciones geográficas de las Indias (Jiménez de la Espada 1885). } \\
\text { [5] }\end{array}$ \\
\hline $\begin{array}{l}\text { Relación geográfica de Gerónimo Luis de } \\
\text { Cabrera (gobernador) }\end{array}$ & 1573 & NOA & \\
\hline $\begin{array}{l}\text { Relación geográfica de Pedro Sotelo } \\
\text { Narváez (teniente gobernador y vecino de } \\
\text { Santiago del Estero) }\end{array}$ & ca. 1582 & NOA & $\begin{array}{l}\text { Geografia y política. La gobernación de Tucumán en 1582, según la Relación } \\
\text { de Pedro Sotelo de Narváez (Gentile 2012). } \\
\text { [6] }\end{array}$ \\
\hline $\begin{array}{l}\text { Relación de Reginaldo de Lizárraga } \\
\text { (religioso dominico) quien estuvo de paso } \\
\text { por el Tucumán con el fin relevar el estado } \\
\text { de los conventos dominicos. }\end{array}$ & ca. 1589 & $\begin{array}{l}\text { Perú, Bolivia, } \\
\text { Chile y NOA }\end{array}$ & $\begin{array}{l}\text { Descripción colonial (Lizárraga } 1916 \text { [1589]). } \\
\text { [7] }\end{array}$ \\
\hline $\begin{array}{l}\text { Obra escrita por el padre José de Acosta } \\
\text { (religioso jesuita) } \\
\text { Vivió en Perú y en México. }\end{array}$ & 1590 & $\begin{array}{l}\text { México, Perú } \\
\text { y referencias al } \\
\text { NOA }\end{array}$ & $\begin{array}{l}\text { Historia Natural y Moral de las Indias (Acosta } 2008 \text { [1590]). } \\
\text { [8] }\end{array}$ \\
\hline \multirow[t]{2}{*}{$\begin{array}{l}\text { Carta de Alonso de Barzana (religioso jesuita) } \\
\text { escrita en la Asunción del Paraguay al P. Juan } \\
\text { Sebastián, su provincial. }\end{array}$} & 1594 & $\begin{array}{l}\text { Paraguay y } \\
\text { NOA }\end{array}$ & $\begin{array}{l}\text { Relaciones geográficas de las Indias (Jiménez de la Espada, 1881). } \\
\text { [9] }\end{array}$ \\
\hline & Siglo XVII & & \\
\hline \multirow{2}{*}{$\begin{array}{l}\text { Descripción general y respuestas de vecinos } \\
\text { a un Interrogatorio. }\end{array}$} & 1608 & $\begin{array}{l}\text { Santiago del } \\
\text { Estero }\end{array}$ & $\begin{array}{l}\text { El Español de la Argentina. (Pérez Sáez y Pérez Sáez 1997). } \\
\text { [10] }\end{array}$ \\
\hline & 1608 & $\begin{array}{l}\text { Nuestra Señora } \\
\text { de Talavera }\end{array}$ & $\begin{array}{l}\text { El Interrogatorio para las Indias Occidentales de } 1604 \text { (Simioli et al. 2017). } \\
\text { [11] }\end{array}$ \\
\hline Ordenanzas escritas por Alfaro (oidor) & 1612 & $\begin{array}{l}\text { NOA y Río de } \\
\text { La Plata }\end{array}$ & $\begin{array}{l}\text { Ordenanzas de Alfaro del Rio de La Plata y Tucumán (Rocca Mones-Ruiz 2017). } \\
\text { [12] }\end{array}$ \\
\hline $\begin{array}{l}\text { Información escrita por vecinos (mayoría } \\
\text { religiosos) }\end{array}$ & 1613 & $\begin{array}{l}\text { Nuestra Señora } \\
\text { de Talavera de } \\
\text { Madrid }\end{array}$ & $\begin{array}{l}\text { Información levantada en Talavera de Madrid para acreditar servicios } \\
\text { prestados por los vecinos e impugnar con ello la obra de Francisco de Alfaro } \\
\text { (Martínez Zuviría, 1939). } \\
\text { [13] }\end{array}$ \\
\hline $\begin{array}{l}\text { Obra escrita por Bernabé Cobo (religioso } \\
\text { jesuita) }\end{array}$ & 1652 & $\begin{array}{l}\text { Perú, y } \\
\text { referencias al } \\
\text { NOA }\end{array}$ & $\begin{array}{l}\text { Historia del Nuevo Mundo (Cobo } 1890 \text { [1652]). } \\
\text { [14] }\end{array}$ \\
\hline
\end{tabular}

El análisis de los documentos fue guiado por los lineamientos metodológicos propuestos desde la etnohistoria (Lorandi y Del Rio 1992; Nacuzzi 2002, 2007) y desde la etnobotánica histórica atendiendo a los problemas y limitaciones que pueden surgir en el estudio de las relaciones entre las personas y las plantas (Hernández Bermejo y Lora González 1996; Yacovleff y Herrera 1934). La lectura estuvo mediada por las preguntas de investigación en que se inserta este trabajo y considerando las respectivas críticas textuales y contextuales (Nacuzzi 2002).
Aunque dentro de la categoría emic de árboles de España o frutos de Castilla que figuran en los documentos analizados se incluyen en ocasiones también menciones a cucurbitáceas leñosas, en el presente trabajo se puso énfasis en el registro de las viñas y los frutales de hábito arbóreo, dejando a las anteriores para futuras publicaciones junto con las hortalizas y, cereales. Se registraron las etnoespecies ${ }^{3}$ de interés en una tabla y, en todos los casos, se infirieron las especies taxonómicas a las que muy probablemente se esté haciendo referencia. 
Nacuzzi (2007) advierte de la necesidad de atender a las ausencias, aquello que no se menciona explícitamente en los textos. En este sentido, se debe considerar el rol de la escritura en el contexto colonial, ya que los autores de las crónicas que en muchos casos recogían la información oral seleccionaron aquello conveniente y la adecuaron a los parámetros occidentales de tiempo y espacio, así como a una lógica propia de verdad/falsedad (Martínez Cereceda 2011; Pease 2004).

\section{Resultados y Discusiones}

La Tabla 3 proporciona un panorama general de las viñas y árboles frutales introducidos que habrían estado presentes en la vida cotidiana de las ciudades del NOA, área comprendida dentro de la Gobernación de Tucumán durante los siglos XVI y XVII. Los resultados se exponen siguiendo la cronología de las fuentes tempranas analizadas, y se diferencian en dos momentos analíticos: (1) el primero comprende desde mediados a fines de siglo XVI y (2) el segundo comprende las primeras décadas del siglo XVII.

\section{Fuentes documentales de mediados a fines del siglo XVI}

Los escritos acerca de la realidad americana fueron mayoritariamente redactados por europeos y dirigidos a autoridades peninsulares que nunca habían cruzado el Atlántico. Por lo tanto, es frecuente encontrar en ellos caracterizaciones realizadas a partir de cualidades análogas a "lo conocido" en aquel continente, como el caso de las plantas a las que les asignaron el nombre de su homóloga europea. El jesuita Bernabé Cobo, quien estaba interesado en rastrear cuáles eran los vegetales que habían sido traídos tempranamente al Virreinato del Perú, indicó las dificultades para distinguirlos de los nativos ya que "... a casi todas las cosas propias de las Indias, fuera de los nombres propios que ellas tienen en las lenguas de los naturales les han puesto los españoles los nombres de aquellas cosas con que éstas tienen alguna semejanza y analogía..." (Cobo 1890 [1652] (1):331). Tal es el caso del algarrobo, que recibió tal nombre por su similitud morfológica y funcional con el algarrobo europeo (Ceratonia siliqua) (Capparelli 2007). Desde la perspectiva occidental, los árboles nativos que conformaban el paisaje tucumano no eran semejantes a los "árboles frutales de Castilla" y por ello eran percibidos como infructíferos, silvestres, espinosos. Por ejemplo, Cobo también señaló: “....Muy pocos son los árboles que cuanto vinieron a esta tierra los españoles hallaron en ella semejantes en especie a los de España; y esos los más son infrutiferos y silvestres..." (Cobo 1890 [1652](2):11). Particularmente en el Tucumán, otro religioso decía: “... los árboles infructíferos, llenos de espinas: los más son algarrobos (...) todas las fructas nuestras (que de la tierre ninguna vi) son de bonísimo sabor..." (Lizárraga 1916 [1589]:229).

Tabla 3. Viñas y árboles frutales mencionados en las ciudades de estudio (siglos XVI y XVII).

\begin{tabular}{|c|c|c|c|c|c|}
\hline Etnoespecies & $\begin{array}{c}\text { Identificación } \\
\text { taxonómica inferida }\end{array}$ & $\begin{array}{l}\text { Santiago del } \\
\text { Estero }\end{array}$ & $\begin{array}{l}\text { San Miguel de } \\
\text { Tucumán }\end{array}$ & $\begin{array}{l}\text { Nuestra Señora de } \\
\text { Talavera }\end{array}$ & Londres \\
\hline $\begin{array}{l}\text { Árboles frutales de } \\
\text { Castilla/de España }\end{array}$ & & {$[6],[10]$} & $\begin{array}{l}\text { [6], Borsella y } \\
\text { Aguirre (2018) }\end{array}$ & {$[6],[11]$} & $\begin{array}{l}\text { Capparelli } \\
\text { et al. (2005) }\end{array}$ \\
\hline Albarcoques & Prunus armeniaca & $\mathrm{s} / \mathrm{d}$ & $\mathrm{s} / \mathrm{d}$ & [11] & $\mathrm{s} / \mathrm{d}$ \\
\hline Ciruelos & Prunus domestica & [6] & $\mathrm{s} / \mathrm{d}$ & $\mathrm{s} / \mathrm{d}$ & $\mathrm{s} / \mathrm{d}$ \\
\hline Duraznos & Prunus persica & {$[6],[10]$} & $\begin{array}{l}\text { Borsella y Aguirre } \\
\text { (2018) }\end{array}$ & [11] & $\mathrm{s} / \mathrm{d}$ \\
\hline Granadas & Punica granatum & {$[6],[10]$} & s/d & [11] & $\mathrm{s} / \mathrm{d}$ \\
\hline Higueras & Ficus carica & $\begin{array}{l}\text { Abad } 1585 \text { en } \\
{[3],[6],[10]}\end{array}$ & $\mathrm{s} / \mathrm{d}$ & [11] & $\mathrm{s} / \mathrm{d}$ \\
\hline Limas & Citrus aurantiifolia & [6] & $\mathrm{s} / \mathrm{d}$ & $\mathrm{s} / \mathrm{d}$ & $\mathrm{s} / \mathrm{d}$ \\
\hline Manzanas & Malus pumila & [6] & $\mathrm{s} / \mathrm{d}$ & [11] & $\mathrm{s} / \mathrm{d}$ \\
\hline Membrillos & Cydonia oblonga & {$[6],[10]$} & $\mathrm{s} / \mathrm{d}$ & [11] & $\mathrm{s} / \mathrm{d}$ \\
\hline Naranjos & Citrus $x$ aurantium & [6] & $\begin{array}{l}\text { Borsella y } \\
\text { Aguirre (2018) }\end{array}$ & [11] & $\mathrm{s} / \mathrm{d}$ \\
\hline Perales & Pyrus communis & [6] & $\mathrm{s} / \mathrm{d}$ & [11] & $\mathrm{s} / \mathrm{d}$ \\
\hline Viñas & Vitis vinifera & $\begin{array}{l}\text { Abad 1585en [3], } \\
{[6],[10]}\end{array}$ & $\begin{array}{l}\text { Borsella y } \\
\text { Aguirre (2018) }\end{array}$ & $\begin{array}{l}{[6],[11],} \\
\text { Marschoff (2018) }\end{array}$ & $\begin{array}{l}\text { Capparelli } \\
\text { et al. (2005) }\end{array}$ \\
\hline
\end{tabular}

Nota: los números corresponden a las fuentes primarias de la Tabla 2; s/d: sin data. En Londres, la referencia corresponde a alguna de sus fundaciones del siglo XVII. 
Esta conceptualización negativa de los primeros años creaba la imagen de un paisaje categorizado como salvaje y poco humanizado, mediante la cual se pretendía legitimar la ocupación del territorio y, a su vez, la necesidad de transformarlo materialmente por medio de la introducción de plantas y animales (Denevan 1992). Si bien estas percepciones variaban según las experiencias de los individuos, la relación con el paisaje será modificada positivamente una vez introducidos los árboles frutales (Mafferra y Marconetto 2017).

Como señalaron Capparelli et al. (2005), el informe escrito por Alonso Abad, en el cual se expresa el estado de pobreza de Santiago del Estero en los primeros años de su fundación, provee de información respecto a un contexto en el que los árboles frutales fueron ingresados a la región desde La Serena, Chile. Dicho informe evidencia además la valoración positiva de los europeos por tales árboles:

...del Reyno de chile traxeron a vn sacerdote clerigo llamado juan cidron y mucha semilla de algodón y plantas de viñas y otros arboles frutales con que estuvieron muy consolados y plantaron algodonales y otras eredades (...) con lo qual [los españoles] se consolaron y se sosegaron y quietaron para permanecer en esta tierra... (Abad 1585 en Levillier 1918:173, 221. El destacado es mío).

La evangelización y el sometimiento de los indígenas para sembrar las plantas pretendidas por los europeos resultaron actividades fundamentales para transformar la experiencia europea en el ambiente tucumano, lo que contribuyó a la relativa estabilidad de la ocupación del territorio. Otro documento contemporáneo evidencia también la preocupación en la preservación de los frutales, ya que un testigo menciona que los árboles -entendiendo que quizás se refiera a plantines- se dejaban bajo el cuidado de un vecino en particular, quizás hasta el momento conveniente para su plantación: “...lo que toca a los arboles fruteros oyo decir que las a enviado a esta ciudad el dicho gobernador francisco de Aguirre y están en poder de Nicolás carrizo vecino desta ciudad por que no se pierdan..." (Santander 1581 en Levillier 1919(1):489).

Retomando la información obtenida del documento escrito por Abad, además de las viñas, el único árbol frutal que se mencionó es la higuera "...e con los arboles higueras viñaseotras cosasquese pusieroneplantaron..." (Abad 1585 en Levillier 1918:117. El destacado es mío). Se establece en principio, que las higueras y las viñas formarían parte del conjunto de 'frutales de Castilla' que habrían ingresado tempranamente a la ciudad de Santiago del Estero y que su ruta de introducción habría sido desde la región de Chile (Capparelli et al. 2005). Cabe la posibilidad que en ese mismo viaje se hayan introducido otros árboles frutales, pero al menos no aparecen mencionados explícitamente.

Para fines del siglo XVI, Santiago del Estero era el núcleo urbano más estable de la Gobernación del Tucumán, y se había convertido en el centro proveedor de recursos humanos y materiales para aquellas otras ciudades que se iban estableciendo (Igareta 2012). Para este entonces, los documentos de Lizárraga (Lizárraga 1916 [1589]) y Sotelo Narváez (Gentile 2012) ofrecen una caracterización general del desarrollo en cada ciudad y, entre otros aspectos, se detienen en su flora. De sus relatos se infiere que, además de las viñas y las higueras, otras especies se habrían incorporado al elenco vegetal de los sitios y se encontraban integradas al paisaje urbano implantado en el NOA.

Lizárraga, quien estaba de paso por la región, en su recorrido observó que “....en toda esta provincia [Tucumán] se dan viñas membrillos, granadas, manzanas etcétera..." (Lizárraga 1916 [1589]:230). Además, recopiló algunos aspectos producto de la adaptación local de estos cultivos, registrando por ejemplo que el salitre del suelo otorgaría buen sabor a los frutos introducidos, que los "árboles duran poco" y que "el vino que se hace dura muy poco, porque se vuelve vinagre" (Lizárraga 1916 [1589]:230). Por otra parte, Sotelo Narváez, quien fuera vecino encomendero de Santiago del Estero, escribía al respecto:

...[los indios] No tienen fruta mas que de cardones diferentes tunas ${ }^{4}$ y algarroba y chañar. Los españoles y ellos tienen ahora frutas despaña que se han plantado, viñas de que se cojen muchas uvas y vino. Durasnos higos melones ${ }^{5}$ membrillos y manzanas granadas perales y ciruelos aun no han dado fruta ay limas y naranjas..." (Sotelo Narváez 1582 en Gentile 2012:599).

Para los europeos el abanico de opciones de frutas nativas resultaba reducido por lo que sus árboles frutales vendrían a satisfacer esa carencia preexistente tanto para los propios españoles como así también, según los dichos de Sotelo Narváez, para los indígenas. Si contextualizamos que el autor formaba parte del grupo de conquistadores, y que este documento, dirigido a las autoridades de la Audiencia de La Plata, se escribió mientras esperaba para declarar a su favor, podríamos cuestionar la intencionalidad de sus dichos. Su lectura íntegra presenta una serie de apreciaciones contradictorias, ya indicadas por Gentile (2012). En este sentido, podría resultar algo exagerado el mencionado consumo de frutas de España por parte de los indígenas, ya que se podría sospechar que lo que pretendía el autor era enaltecer ciertas acciones y demostrar posiciones de benevolencia como representante del grupo de los encomenderos. Aun así, el testimonio brinda 
información acerca de las especies que abarcaba el concepto 'árboles frutales de España' y que en otros documentos no se habían detallado.

Por último, interesa destacar de la descripción de este encomendero el momento en que los pobladores de la ciudad de Córdoba se encontraban cultivando estas especies frutales. Probablemente, ciertos resultados exitosos iniciales en el cultivo de cereales europeos, sumados a la disponibilidad de mano de obra indígena y a la consiguiente estabilidad de la vida en la ciudad, darían pie a sus habitantes a aventurarse en el cultivo de las viñas y árboles frutales: “...Van los cristianos poniendo viñas y danse bien siembran de regadío y temporal porque los cristianos han sacado acequias cojen trigo maíz y cebada y todas legumbres y otras semillas de España, van poniendo arboles de castilla es tierra aparejada para ello..." (Sotelo Narváez 1582 en Gentile 2012:605).

\section{Fuentes documentales de las primeras décadas del siglo XVII}

Para esta etapa la información fue obtenida principalmente a partir de las respuestas de un grupo de pobladores a los interrogatorios realizados en las ciudades a pedido de las autoridades peninsulares, con el fin de controlar los territorios americanos. En relación al Tucumán, únicamente se conservan en el Archivo Nacional de Bolivia las correspondientes a tres ciudades (Simioli et al. 2017) y en este trabajo se analizaron las dos que han sido transcriptas y publicadas: la de Santiago del Estero (Pérez Sáez y Pérez Sáez 1997) y la de Nuestra Señora de Talavera (Simioli et al. 2017). Estos relevamientos constaban de 355 preguntas y solo algunas de ellas fueron contestadas inicialmente por los tenientes de gobernador y justicia de las respectivas ciudades mediante una descripción general. Luego figuran las respuestas individuales de algunos habitantes en las cuales se enfocó en lo relativo a las especies de interés.

El estudio de estos interrogatorios permitió conseguir un detalle mayor de los cultivos presentes en las ciudades, ya que algunos de los vecinos los declararon como parte de sus bienes especificando cantidades, espacios de cultivo, usos, quiénes se ocupaban de ellos y algunos datos en cuanto al rendimiento. En el documento de la ciudad de Santiago del Estero, por ejemplo, la descripción general fue escrita por su teniente de gobernador y justicia Alonso de Herrera, quien señala respecto a los cultivos: “... en saliendo de la çiudad entra el canpo: por una parte se va a tomar al rrio y por la otra salida, a la açequia principal donde estan las chacaras para el sustento de los vezinos della..." y que de ellas se ha obtenido más de seiscientas arrobas de vino y "...frutas se cogen y dan en la tierra la mayor parte de las que ay en españa por qu>el temperamento de la tierra es bueno..." (Herrera 1608 en Pérez Sáez y Pérez Sáez 1997:1821). A continuación de su declaración se encuentran las respuestas de 95 habitantes de la ciudad.

Del total de las respuestas, trece vecinos declararon tener árboles frutales entre sus posesiones. Se intentó establecer si estos individuos tenían un origen común español, pero se observó que, a diferencia de lo esperado, los orígenes declarados incluían españoles, portugueses, algunos que venían del Perú, otros de Chile y también criollos nacidos en la ciudad. Los árboles frutales mencionados incluían duraznos, membrillos, higueras, granados y, salvo escasas excepciones, estos mismos individuos tendrían también viñas.

Con respecto a la localización de todos los cultivos declarados, surgió la diferenciación de dos áreas principales: por un lado, las chacras ${ }^{6}$ que estaban sobre la acequia principal y próximas al emplazamiento del núcleo urbano, y por otro lado, algo más distanciadas, las chacras ubicadas en los pueblos de indios, en las cuales se sembraría principalmente maíz, trigo, cebada y algodón. En la mayoría de los casos declarados se mencionó explícitamente la ubicación de los árboles frutales en las chacras ubicadas sobre la acequia principal de la ciudad, y ninguno explicitó haberlos plantado en los pueblos de indios, como sí sucedió por ejemplo con los sembradíos de cereales que se realizaban en ambas áreas.

En cuanto a las cantidades de árboles frutales declarados, hay quienes mencionaron tener entre $10 \mathrm{y}$ 30 pies de algún frutal en particular, otros declararon tener 2.000 sarmientos de varias especies, y otros en cambio, poseían "algunos árboles" o "alguna arboleda". Por ejemplo, Leonor de Cameros vecina encomendera declara: “...tengo asimesmo en la acequia principal desta ciudad una media chacara donde ay arboles frutales y una viñuela de tres o quatro mil çepas pocas mas o menos con un yndio q' la guarda..." (Pérez Sáez y Pérez Sáez 1997:70). En cuanto al motivo de la posesión de estos cultivos, García Barata declara que no son comercializables sino que están destinados al consumo familiar: “...y tengo casa poblada en esta çiudad - y dos chacaras La Una poblada la mitad della y la otra despoblada por tener pocos yndios - y la media que tengo poblada tiene dos mill sarmientos muchos duraznos y menbrillos y higueras para el sustento de mi casa - q'desto no se vende nada..." (Pérez Sáez y Pérez Sáez 1997:63).

Si pasamos al cultivo de las viñas, dieciséis personas del total de las interrogadas tendrían dicho cultivo y, como ya se mencionó, la mayoría también disponía de especies de árboles frutales. En cuanto a su localización, quienes poseían ambos tipos de cultivos los ubicaron en el mismo espacio correspondiente a las chacras cercanas a la ciudad. Solo cuatro poseían únicamente viñas y no 
resulta claro el espacio en el que estas se hallaban, a excepción de Gerónimo Pereira Bustillo, quien explicita su plantación en el pueblo de indios:

Por causa de que los dicho yndios a mi encomendados heran pocos (...) y que en ninguna manera me podia sustentar con ellos con hilados y otras rrentas que dan rrepartimientos grandes me dispuse a plantar una uiña en el dicho mi pueblo de doce mill cepas de la qual tengo algun prouecho de dos años a esta parte que es desde que comiença a dar fruto y esta es la hazienda que al presente tengo... (Pérez Sáez y Pérez Sáez 1997:75. El destacado es mío).

La cantidad que declaró este vecino (12.000) es llamativa en relación a lo que declaró el resto (entre 2.000 y 4.000 cepas de viñas). Esta amplia diferencia así como la ubicación de este cultivo sería justificada por el hecho de que Pereira Bustillo destinó sus viñas a obtener beneficios económicos.

Las respuestas de los vecinos de la ciudad de Nuestra Señora de Talavera se obtuvieron en el año 1608 , momento en el que se intentaba trasladar la ciudad luego de haber quedado su emplazamiento original fuera del principal camino de circulación regional (Simioli et al. 2017). La descripción inicial fue realizada por el teniente gobernador, Diego López Correa, quien declaró respecto a la ubicación de la acequia y las chacras:

...las casas no tienen huertas ni jardines ni fuentes. Y al principio quando se poblo esta çiudad, de la acequia que riega las chacaras se traia agua a la çiudad por sus acequiones y porque se criava salitre y haçia daño a las casas la quitaron (...) la çiudad no tiene fuente ninguna dentro de si ni acequia y esta fundada junto a un rio de buen agua de donde beve. Y dos leguas della esta la toma de una açequia que pasa por çerca desta çiudad y riega todas las chacaras y huertas que los vezinos e moradores tienen para su sustento. $Y$ algunas estan luego al salir desta çiudad y las que mas lejos una legua... (López Correa 1608 en Simioli et al. 2017:13).

En vinculación a la pregunta sobre los cultivos europeos en la ciudad, mencionó algunas especies de árboles frutales: “...Ay naranjos, cojense peras, albarcoques, brevas higos ${ }^{7}$, granadas, ubas, melones, pepinos $^{8}$, menbrillos, mançanas, durasnos..." (López Correa 1608 en Simioli et al. 2017:17).
A diferencia del documento anterior, en este caso ninguno de los sesenta y nueve individuos interrogados mencionó en sus declaraciones a los árboles frutales, aunque sí declararon la tenencia de viñas. Se contabilizaron dieciséis propietarios de viñas, nueve de los cuales las tendrían en chacras de la ciudad; dos en el pueblo de indios; uno en ambos espacios; en tres casos, no resultó clara su ubicación; y por último, uno de los vecinos las tendría en Paraguay. Respecto a las cantidades declaradas, estas oscilaron entre 3.000 a 10.000 cepas, y en ocasiones indicaron que obtenían entre 10 y 50 arrobas de vino. El motivo alegado del cultivo era para el sustento de su casa y familia. Además, algunos comentaron que las viñas daban uva en esta tierra a los 3 años, que por la mala comodidad de la tierra no dan casi fruto y que "se coge tam poco por estar la guarda de las binas en poder de indios y lo que se coge se buelve binagre" (Simioli et al. 2017:26). La mala conservación del vino era una cuestión que ya había sido registrada por el fraile Lizárraga en su descripción del Tucumán. ¿Se debería a la falta de conocimiento de prácticas de cultivo adecuadas? ¿Sería un comentario del encomendero para justificar la supuesta actitud de holgazanería de los indios y lo poco que obedecían al mandato español? ¿Se estaría refiriendo a que era un producto de consumo estimado por los indígenas? ¿O simplemente, como otro vecino había argumentado, se debía a las inadecuadas características ambientales locales?

\section{Nuevas prácticas, nuevos actores}

En términos generales, se estableció que la mayor parte de las viñas y los árboles frutales declarados habrían compartido el espacios, de cultivo en las chacras próximas al núcleo urbano. En este sentido, se debe contemplar que muchas de las acciones declaradas por los vecinos y autoridades de las ciudades coloniales apuntaban a mostrarse en consonancia con lo establecido en la normativa vigente. Aunque en lo que refiere a estas especies, en las ordenanzas dictadas por Abreu de 1576 no se halló ninguna referencia al respecto, sí ordenaban que en el pueblo de indios solo cultiven trigo, maíz, cebada y algodón. Además, el rol preponderante que ocuparon los cereales y el algodón en el comercio regional (Assadourian 1982) influyó en que los encomenderos pretendieran mayores extensiones de estos cultivos disponiendo también de las tierras dejadas a los indígenas en los pueblos de indios. Posteriormente, en las ordenanzas de Alfaro en 1612 sí se encontraron referencias a que los encomenderos quiten sus viñas y demás haciendas de los pueblos de indios estableciendo su ubicación permitida a cierta distancia mínima de estos. Esta regulación y las declaraciones poco precisas 
de algunos vecinos en los interrogatorios, evidenciarían que para inicios del siglo XVII, los encomenderos habrían avanzado con otros cultivos, al menos con las vides, fuera del área estrictamente urbana.

Otro aporte que surgió de los interrogatorios fue la emergencia de nuevos actores sociales vinculados a los trabajos domésticos, agrarios y ganaderos. En las chacras de la ciudad disponían de una parte de los indígenas encomendados separados de su repartimiento y obligados a trabajar bajo la forma de servicio personal. En algunos casos los encomenderos declararon tener mayordomo o poblero quién, aparentemente, sería el administrador de estos espacios, y se destaca porque "entiende del beneficio de su hacienda" (Simioli et al. 2017:34). La filiación étnica de los mayordomos era variada, pudiendo ser en algunos casos de origen español, mestizo o indígena. Cabe la posibilidad que poseer ciertos conocimientos y establecer lazos de confianza con el encomendero les otorgara una posición más favorable dentro del sistema colonial por lo que habrían cumplido un rol clave en el funcionamiento de las encomiendas, actuando como mediadores entre el "mundo hispano" y el "mundo nativo" (González Navarro 2012). En los casos en que se declara la imposibilidad del pago de mayordomo, la guarda de las haciendas se encontraría a cargo de indios yanaconas, quienes, por ejemplo, para el caso de la ciudad de Esteco son caracterizados como aquellos que hablan el quechua. Asimismo, hay vecinos que declaran ser ellos mismos quienes estaban a cargo o quienes se ocupaban en sembrar y cosechar con algún indio alquilado.

El cultivo de las viñas y los árboles frutales requería de modos particulares de irrigación, de reproducción a través de injertos y de conservación propios de la tradición hispanoárabe (Castro et al. 2015). A pesar del contexto asimétrico de poder, la incorporación de nuevas prácticas entre los indígenas dio lugar a nuevas tradiciones, tales como las observadas por Cobo en Perú, en las que la experimentación e invención representaron mejoras en los resultados agrícolas:

...Todos los árboles frutales de las Indias son en muchas partes silvestres, la fruta de los cuales no se diferencia en calidad de la que llevan los arboles hortenses, porque los indios hacían muy poco beneficio a los que criaban en sus huertas, por no haber tenido conocimiento del arte de ingerir unos en otros, mas después que los españoles habitan esta tierra, han hecho varios ingertos asi de unos árboles de la tierra con otros, como destos con los de Castilla, con que las frutas se han mejorado mucho... (Cobo 1890 [1652](II):10).
...En los valles de La Nasca han dado de pocos años aca en pisar la uva metida en costales o sacas de melinge, y sale el vino mucho mas puro, claro y blanco, de manera que tiene mas valor que lo demás que no es de costales. El origen de esta invención fue que como un indio no tenía lagar en que pisar la uva de un parralillo suyo a necesidad la piso en unos costales de lienzo y viendo que el vino que saco hacia ventaja a lo demás, aprendieron los españoles de lo que el indio hizo por necesidad... (Cobo 1890 [1652](II):380).

En relación al NOA, además, se registró que las menciones a "árboles frutales de Castilla", "árboles fruteros", "frutas nuestras/de España", refirieron a especies cultivadas en su mayoría de hábito arbóreo y en menores ocasiones incluyó además alguna de estas tres Cucurbitáceas: sandías, melones y pepinos. Por otro lado, las menciones a "frutas de la tierra", "árboles frutales de las Indias", refirieron a especies arbóreas silvestres asociadas al monte -como el algarrobo, el chañar y el mistol- y principalmente de consumo indígena. Solo en una ocasión se registró una percepción diferente de las frutas nativas, al parecer incluidas en el consumo español: “. ... ay frutas y semillas de la tierra, axi, asafran, tunas. El axi sirbe de salsa y en lugar de pimienta y mostasa, el asafran no es tam buena como el de Castilla y las tunas es buena fruta y asimismo se cojen sandias y calabaças..." (López Correa 1608 en Simioli et al. 2017:17). Posiblemente esta apreciación por los frutos nativos se vincule a su presencia en los espacios hortícolas.

También en los documentos se encontraron menciones a espacios de almacenamiento y de comercialización al interior de las ciudades. Por ejemplo, para la ciudad de Esteco, "...ni esta çiudad tiene arravales ni casas fuera del circuito della si no es algunas de tierra que ay en las chacaras a donde se encierra la comida y vino que cojen..." (Simioli et al. 2017:13). En cuanto a la comercialización de los productos, dos declarantes de la ciudad de Santiago, indican que trabajaban en una pulpería donde vendían vinos propios y de otros comerciantes (Pérez Sáez y Pérez Sáez 1997). En la ciudad de Nuestra Señora de Talavera, López Correa indica que la cantidad habitualmente obtenida de vino solo alcanzaba a abastecer parte del consumo local, y por ello se proveían además de la producción de otras regiones aledañas como el Paraguay y Chile (Simioli et al. 2017). A juzgar por la declaración de Pedro Flores, confitero que alquilaba una tienda en la calle de los mercaderes en Santiago del Estero, los frutales también formarían parte de la comercialización (Pérez Sáez y Pérez Sáez 1997). 
La manipulación cotidiana de las viñas y árboles frutales implicó ciertas articulaciones entre las plantas nativas y exóticas. Las maderas nativas habrían sido usadas en la construcción de espacios productivos tales como los secaderos para la deshidratación de frutos (Lacoste et al. 2011), y la preparación de confituras y dulces requirió de la caña de azúcar traída del Paraguay (Lizárraga (1916 [1589]). Otros ejemplos en este sentido nos brinda Cobo (1890 [1652]), registrando que la resina extraída del algarrobo era utilizada para marcar las vasijas de vino y que de su madera se hacían las estacas empleadas en las viñas. También, describe que los negros que trabajaban en las viñas del Perú usaban una guirnalda de hojas de molle para espantar insectos. Cabe resaltar, que de la extensa recopilación que realiza este jesuita acerca de las plantas, únicamente en dos ocasiones menciona el uso que hace de ellas la población africana.

Finalmente, los resultados obtenidos del análisis documental, permiten proponer algunos indicadores arqueológicos sobre la presencia de las viñas y los árboles frutales en las ciudades coloniales tempranas del NOA. En principio, restos botánicos correspondientes a las especies relevadas (Tabla 3), cuyas evidencias de cultivo serían esperables principalmente en áreas asociadas a las acequias de los sitios urbanos. De igual modo, en estas áreas, en sectores que presenten restos de arquitectura de barro, se esperan evidencias del almacenamiento de los frutos cosechados y del vino producido. Sería esperable también hallar registro material relativo a herramientas agrícolas, estacas de algarrobo, contenedores cerámicos y/o de fibras vegetales. Los espacios destinados a la elaboración de vino no fueron registrados, pero se podría proponer que dicha actividad se haya realizado en proximidad al sector de almacenamiento. En el área habitacional del núcleo urbano, se esperan evidencias de consumo doméstico, ya sea microrrestos asociados a vasijas, partes no consumibles del fruto en áreas de descarte o restos de leño en áreas de fogones. Una mayor concentración de estas evidencias podría estar asociada al sector de comercialización de estos productos. En términos generales, se podría señalar una posible microcirculación de los frutos desde los espacios de cultivo, almacenamiento y procesamiento en las chacras hacia los espacios de consumo doméstico y comercialización al interior de las ciudades.

\section{Conclusiones}

La introducción de especies vegetales europeas al NOA durante el siglo XVI fue un medio para el sometimiento indígena y así afianzar la ocupación ibérica en el territorio. Si bien las menciones de plantas en las fuentes escritas pueden resultar ambiguas debido a las transferencias culturales que realizaron los cronistas, se registró un amplio conjunto de etnoespecies leñosas exóticas cultivadas en los espacios urbanos. Las primeras menciones registradas de este grupo refirieron a la introducción de viñas e higueras desde Chile a la ciudad de Santiago del Estero, a mediados del siglo XVI. Para fines de este siglo, el paisaje urbano implantado en el NOA incluía, además de las especies ya mencionadas, ciruelos, duraznos, granadas, limas, manzanas, membrillos, naranjas y perales. La presencia de estas plantas habría transformado la experiencia europea en la región tucumana antes percibida como carente de frutos adecuados para consumo español.

Para la primera década del siglo XVII se consiguió un detalle mayor de los cultivos presentes en las ciudades, ya que algunos de los vecinos los declararon como parte de sus bienes especificando las cantidades, los espacios de cultivo, quiénes se ocupaban de ellos y algunos datos en cuanto al rendimiento y a la adaptación local. En este periodo las etnoespecies registradas fueron: viñas, higueras, albaricoques, duraznos, granadas, manzanas, membrillos, naranjas y peras.

En principio, se estableció que las viñas y los árboles frutales habrían sido cultivados de manera conjunta en las chacras ubicadas en la acequia principal de la ciudad o próximas a ella. A diferencia del cultivo de cereales cuya mención se asoció tanto a las chacras de la ciudad como en pueblos de indios. Con respecto a las viñas en particular, las Ordenanzas de 1612 y las declaraciones de algunos vecinos hacen suponer que para el siglo XVII, en algunos casos, habrían avanzado con su cultivo en el pueblo de indios. El sistema colonial implicó la emergencia de nuevos actores sociales como mayordomos o pobleros vinculados a los trabajos en las chacras, y pulperos y confiteros vinculados a la comercialización de los productos. Según lo registrado al menos en Perú, las nuevas prácticas agrícolas entre los indígenas dieron lugar a nuevas tradiciones en las que la experimentación e invención representaron mejoras en los resultados obtenidos. Los registros de las menciones a "árboles frutales de Castilla", "frutas nuestras", fueron comparadas con las menciones a los "frutos de la tierra", "árboles frutales de las Indias" halladas en los documentos, señalando que en el primer caso se hacía referencia en gran parte a especies de hábitat arbóreo propias de espacios hortícolas, y en el segundo se incluía especies arbóreas silvestres, asociadas al monte y al consumo indígena.

En relación a los antecedentes arqueológicos recopilados, solo en dos sitios se cuenta con evidencias de viñas y árboles frutales. En el sitioEl Shincal (Catamarca), en el que se recuperaron, entre otros cultivos nativos y exóticos, restos de endocarpos de duraznos, en un contexto ritual de manipulación indígena datado a mediados del siglo XVII. Y el segundo caso, que corresponde a un contexto de descarte doméstico, en el área fundacional de la ciudad de Mendoza en el que 
fueron recuperados restos de endocarpos de duraznos, olivo y semillas de vid; y restos de carbón de duraznero, de alguna pomácea (posiblemente membrillero, manzano o peral) y de la vid. En ambos casos, los investigadores propusieron el ingreso de los cultivos a estos sitios por parte de los indígenas. Si bien el análisis documental realizado en este trabajo solo dispuso de las declaraciones de europeos, los antecedentes señalados dan cuenta de la posibilidad que en las ciudades y/o en espacios con menor control español también haya circulación de los cultivos exóticos por parte de las poblaciones nativas.

Finalmente, se propusieron algunos indicadores arqueológicos sobre la presencia de estas especies vegetales en las ciudades coloniales tempranas del NOA. Cabría esperar evidencias del cultivo de las viñas y de los árboles frutales relevados asociadas a las acequias de las ciudades. Asimismo, en las chacras y al interior de recintos de tierra cruda, cabría esperar evidencias de almacenamiento e implementos agrícolas, como así también una posible zona de procesamiento de los frutos. En el área habitacional del núcleo urbano cabría esperar evidencias de su consumo doméstico y/o de su comercialización, por ejemplo, microrrestos asociados a vasijas, partes no consumibles de los frutos en áreas de descarte, carbones en área de fogones. En términos generales, se podría señalar una posible microcirculación de los frutos desde los espacios de cultivo, almacenamiento y procesamiento en las chacras hacia los espacios de consumo doméstico y comercialización al interior de las ciudades.

Agradecimientos: Al CONICET. A mis directoras Aylén Capparelli y Ana Igareta que me guían en esta investigación. A Diego Gobbo y Meli Auge por la elaboración de la figura y a Esteban Hernández Bermejo y Tany Pochettino por la amable respuesta a algunas inquietudes. A los evaluadores por sus comentarios que han ayudado a mejorar el escrito.

\section{Referencias Citadas}

Acosta, J. 2008 [1590]. Historia Natural y Moral de las Indias. Editado por Fermín del Pino-Díaz. Editorial CSIC, Madrid.

Ardissone, R. 1961. Lineamientos de la instalación humana en el Bolsón de Pipanaco. Anales de la Sociedad Argentina de Estudios Geográficos IX:171- 244.

Assadourian, C. 1982. El Sistema de la Economía Colonial. Mercado Interno, Regiones y Espacio Económico. IEP Ediciones, Lima.

Báez, J.1947. La primera colonia agrohispana en el Tucumán (siglo XVI). Revista Argentina de Agronomía 14:85-93.

Bibar, G. 1966 [1558]. Crónica y Relación Copiosa y Verdadera de los Reynos de Chile. Fondo Histórico y Bibliográfico "José T. Medina”. Editorial Universitaria S.A., Santiago.

Borsella, F. y M.G. Aguirre 2018. Ambiente y recursos naturales durante la ocupación de la ciudad de San Miguel de Tucumán (siglos XVI y XVII). Revista de Arqueología Histórica Argentina y Latinoamericana 12:434-453.

Cámara Hernández, J.A., M. Alzogaray, R. Bellón y A.J. Galmarini 2012. Razas de Maíz Nativas de la Argentina. Ed. Fac. Agronomía, Universidad de Buenos Aires, Buenos Aires.

Capparelli, A. 2007. Los productos alimenticios derivados de Prosopis chilensis (Mol.) Stuntz y P. flexuosa DC., Fabaceae, en la vida cotidiana de los habitantes del NOA y su paralelismo con el algarrobo europeo. Kurtziana 33:1-19.

Capparelli, A. 2009. Intra-site comparison of the archaeoethnobotanical evidence of El Shincal: implicances to the Inka economy. En La Alimentación en la América Precolombina y Colonial: Una Aproximación Interdisciplinaria, coordinado por A. Capparelli, A. Chevalier y R. Piqué, pp. 113-144. Consejo Superior de Investigaciones Científicas (CSIC) - Treballs d'Etnoarqueologia, Madrid.

Capparelli, A., V. Lema, M. Giovannetti y R. Raffino 2005 Introduction of European crops (wheat, barley and peach) in Andean Argentina during the $16^{\text {th }}$ century: Archaeobotanical and ethnohistorical evidence. Vegetation History and Archaeobotany 14:472-484.
Castillon, V., A. Capparelli y A. Igareta 2019. Modos de uso y circulación de vegetales en contextos urbanos del Tucumán colonial (siglos XVI y XVII): una aproximación con énfasis arqueobotánico. Investigación Joven 6:125-125.

Castro A., P. Lacoste, J.A. Yuri, M. Aranda, N. Soto, M. Solar y C. Chávez 2015. El arte de cultivar frutales. Injertos en pomáceas, carozos, cítricos y nueces (Chile y Cuyo, 1550-1850). En Frutales, Cultura y Sociedad. Un Recorrido Histórico de la Fruticultura Universal, y los Orígenes de la Fruticultura Chilena hasta Nuestros Días, compilado por P. Lacoste y J.A. Yuri, pp 221-236. Editorial Universidad de Talca, Talca.

Chiavazza, H. y L. Mafferra 2007. Estado de las investigaciones arqueobotánicas en Mendoza y sus implicancias en la arqueología histórica. Revista de Arqueología Histórica Argentina y Latinoamericana 1:127-152.

Cobo B. 1890 [1652]. Historia del Nuevo Mundo. Editado por M. Jiménez de la Espada. Sociedad Bibliófilos Andaluces, Sevilla.

Denevan, W.M. 1992. The pristine myth: the landscape of the Americas in 1492. Annals of the Association of American Geographers 82 (3):369-385.

Farberman, J. 2006. Recolección, economía campesina y representaciones de los montaraces en Santiago del Estero, siglos XVI a XIX. Prohistoria 10:11-26.

Gentile, M.E. 2005. Contexto sociopolítico de una encomienda temprana del área andina argentina. Revista Histórica 16:289-330.

Gentile, M.E. 2008. Notas para la etnohistoria de las chacras de coca en la Gobernación de Tucumán (siglos XVI - XVII). Revista de Antropología 6:63-72.

Gentile, M.E. 2009. Noticias tempranas sobre tres recursos naturales de la Gobernación de Tucumán. Bibliographica Americana 5:1-10.

Gentile, M.E. 2012. Geografía y política. La gobernación de Tucumán en 1582, según la Relación de Pedro Sotelo de Narváez. Anuario Jurídico y Económico Escurialense XLV:581-608.

Giovannetti, M. 2005. La conquista del noroeste argentino y los cultivos europeos. Fronteras de la Historia 10:253-283. 
Giovannetti, M. y V. Lema 2005. Los cultivos europeos y la vida aborigen bajo dominio español: apropiación y consumo de trigo en La Rioja de fines del siglo XVII. Actas del VI Congreso Internacional de Etnohistoria, pp. 1-18. Facultad de Filosofía y Letras, Universidad de Buenos Aires, Buenos Aires.

GonzálezNavarro, C. 2012. Pobleros, mayordomos y administradores en el mundo rural cordobés (1580-1650). Surandino Monográfico II(2). Recuperado a partir de http://revistascientificas.filo.uba.ar/ index.php/surandino/article/view/5915.

Hernández Bermejo, J.E. y A. Lora Gonzalez 1996. La documentación histórica y bibliográfica como fuente de información y evidencia etnobotánica. Monografías del Jardín Botánico de Córdoba 3:39-50.

Igareta, A. 2012. Arqueología de Santiago del Estero colonial: historia de varias ciudades. En Ciudades y Territorio en América del Sur del Siglo XV al XVII, compilado por J. Buján, pp. 235-263. Editorial Nobuko, La Plata.

Igareta, A. 2019. Evidencias arqueológicas del uso del barro como materia prima en la arquitectura argentina del período colonial temprano. Anales de Investigación en Arquitectura 9 (1):7-24.

Jiménez de la Espada, M. (ed.). 1881. Relaciones Geográficas de las Indias. Perú (2). Editorial Tipografía de Manuel G. Hernández, Madrid.

Lacoste, P., J.A.Yuri, M, Aranda, A, Castro, K. Quinteros, M. Solar y C. Chávez 2011. Frutales y agroindustria: conservas, aceites y maderas (Chile y Cuyo, 1550-1850). Revista de Indias 71 (253):859-888.

Lambaré, D.A. 2015. Procesos Locales de Selección Cultural en Poblaciones Frutales de la Familia Rosaceae, Originarias del Viejo Mundo Utilizados por Comunidades Rurales del Noroeste Argentino. Tesis doctoral, Facultad de Ciencias Naturales y Museo, Universidad Nacional de La Plata, La Plata.

Lema, V. y A. Capparelli 2007. El algodón (Gossypium sp.) en el registro arqueológico del noroeste argentino su presencia pre y post-hispánica. En Paleoetnobotánica del Cono Sur: Estudios de Casos y Propuestas Metodológicas, compilado por B. Marconetto, P. Babot y N. Olizweski, pp. 49-78. Centro Editorial de la Facultad de Filosofía y Humanidades, Universidad Nacional de Córdoba, Córdoba.

Levillier, R. 1918. Gobernación del Tucumán. Correspondencia de los Cabildos en el Siglo XVI. Sucesores de Rivadeneyra. Madrid.

Levillier, R. 1919. Gobernación del Tucumán. Probanzas de Méritos y Servicios de los Conquistadores. Sucesores de Rivadeneyra, Madrid.

Levillier, R. 1920. Gobernación del Tucumán. Papeles de los Gobernadores en el Siglo XVI. Sucesores de Rivadeneyra, Madrid.

Lizárraga, R. de 1916 [1589]. Descripción Colonial. Editado por Ricardo Rojas. Librería La Facultad. Buenos Aires.

López Cámpeny, S.M.L. y C. Taboada 2016. Primera evidencia arqueológica directa de hilado de algodón en Santiago del Estero (Tierras bajas, Argentina). Temporalidades, contextos y prácticas en juego. Actas XIX Congreso Nacional de Arqueología Argentina, pp.1779-1785. Facultad de Ciencias Naturales e I.M.L., Universidad Nacional de Tucumán, San Miguel de Tucumán.

Lorandi, A.M. y M. del Río 1992. La Etnohistoria. Etnogénesis y Transformaciones Sociales Andinas. Centro Editor de América Latina, Buenos Aires.

Mafferra, L. 2011. Interpretaciones del registro arqueobotánico en arqueología histórica. En Temas y Problemas de la Arqueología Histórica, editado por M. Ramos, A. Tapia, F. Bognanni, M. Fernández,
V. Helfer, C. Landa, M. Lanza, E. Montanari, E. Néspolo y V. Pineau, pp.43-52. Universidad Nacional de Luján, Buenos Aires.

Mafferra, L., H. Chiavazza y F.R. Juñent 2015. El árbol que da frutos, se corta y se echa al fuego. Discusiones sobre el uso de la leña en la Mendoza colonial. Comechingonia 19 (2):203-234.

Mafferra, L. 2018. Prácticas en torno al uso de la leña de plantas introducidas en la ciudad colonial de Mendoza. Revista de Arqueología Histórica Argentina y Latinoamericana 12:1373-1375.

Mafferra, L. y B. Marconetto 2017. Sin un árbol que dé alegría. Experiencias del paisaje nativo y colonial en Mendoza entre los siglos XVI y XIX. Corpus. Archivos Virtuales de la Alteridad Americana 7 (2) (https://doi.org/10.4000/corpusarchivos.1939).

Marschoff, M. 2018. Movilidad, habitantes y experiencias del paisaje: los lugares de Esteco (Salta, Argentina, S. XVI-XVII). Revista de Arqueología Histórica Argentina y Latinoamericana, 12:479-506.

Marschoff, M., C. Castiñeira y J. Simioli 2014. Arqueoestratigrafía de referencia para el registro de la ocupación humana durante los siglos XVI y XVII en la localidad Esteco I, Departamento de Anta, Salta, Argentina. Chungara Revista de Antropología Chilena 46 (3):355-374.

Martínez Cereceda, J.L. 2011. Gente de la Tierra de Guerra. Los Lipes en la Tradición Andina y en el Imaginario Colonial. Fondo Editorial de la Pontificia Universidad Catolica del Perú - Dirección de Bibliotecas, Archivos y Museos de Chile, Lima.

Martinez Zuviría, G. 1939. Información levantada en Talavera de Madrid para acreditar servicios prestados por los vecinos e impugnar con ello la obra de Francisco de Alfaro. Revista de la Biblioteca Nacional 11:411-612.

Marzocca, A. 1959. Historia de Plantas Tintóreas y Curtientes. Instituto Nacional de Tecnología Agropecuaria, Buenos Aires.

Nacuzzi, L. 2002. Leyendo entre líneas: una eterna duda acerca de las certezas. En Historias y Estilos de Trabajo de Campo en la Argentina, compilado por S. Visacovsky y R. Guber, pp. 229-262. Antropofagia, Buenos Aires.

Nacuzzi, L. 2007. La empatía entre las fuentes escritas y nuestras hipótesis de trabajo: una tensión a resolver. Fuentes e Interdisciplina $15-23$

Noli, E. 1998. Algarrobo, maíz y vacas. Los pueblos indios de San Miguel del Tucumán y la introducción de ganados europeos (1600-1630). Mundo de Antes 1:31-63.

Noli, E. 1999. La recolección en la economía de subsistencia de las poblaciones indígenas: una aproximación a través de las fuentes coloniales (piedemonte y llanura Tucumano-santiagueña). Gobernación del Tucumán. En En los Tres Reinos: Prácticas de Recolección en el Cono Sur de América, editado por C.A. Aschero, M.A. Korstanje y P.M. Vuoto, pp. 205-216. Magna Publicaciones, Tucumán.

Noli, E. 2001. Indios ladinos del Tucumán colonial: los carpinteros de marapa. Andes 12:1-31.

Pease, F. 2004. Los Últimos Incas del Cuzco. Instituto Nacional de Cultura, Lima.

Pérez Sáez, V.J. y M.F. De Pérez Sáez 1997. Descripción general de Santiago del Estero y respuestas de sus vecinos al Memorial de 1608. En El Español de la Argentina. Documentos para su Historia (Noroeste), editado por V.J. Pérez y M.F de Pérez, pp. 17-108. Consejo de Investigación, Universidad Nacional de Salta, Salta.

Pochettino, M.L. 2015. Botánica Económica. Las Plantas Interpretadas según Tiempo, Espacio y Cultura. Sociedad Argentina de Botánica, Buenos Aires. 
Porterie, A.P. y J. Simioli 2018. La población de Nuestra Señora de Talavera a comienzos del siglo XVII: españoles, montañeses y extranjeros en el Interrogatorio de 1604. Teoría y Práctica de la Arqueología Histórica Latinoamericana 7:83-89.

Rocca-Mones Ruiz, C.G. 2017. Las ordenanzas de Alfaro del Río de La Plata y del Tucumán 1612. Revista Cruz del Sur 26:385-460.

Rosso, C.N. 2013. La etnobotánica histórica: el caso mocoví en la reducción de San Javiera en el siglo XVIII. Revista Etnobiología 11 (3):54-65.

Sica, G. 2005. "Maíz y trigo; molinos y conanas; mulas y llamas". Tierras, cambio agrario, participación mercantil indígena en los inicios del sistema colonial. Jujuy. Siglo XVII. En Jujuy, Arqueología, Historia, Economía y Sociedad, compilado por D. Santamaría, pp. 106-124. CEIC-Ediciones El Duende, San Salvador de Jujuy.

Simioli, J., A. Porterie y M. Marschoff 2017. El interrogatorio para las Indias Occidentales de 1604 y los informes remitidos por el teniente de gobernador, vecinos, moradores y residentes de Nuestra Señora de Talavera en 1608. Presentación y transcripción completa. Corpus. Archivos Virtuales de la Alteridad Americana 7 (1) (https://doi.org/10.4000/corpusarchivos.1888).

Yacovleff, E. y F.L. Herrera 1934. El mundo vegetal de los antiguos peruanos. Revista del Museo Nacional 3 (3):243-322.

\section{Notas}

${ }^{1}$ Refiere al raquis y las glumas de los granos (Cámara Hernández et al. 2012)

${ }^{2}$ Se denomina grana al producto colorante rojo que se obtiene de la cochinilla (Dactylopius sp.) que parasita a especies de Opuntia (Marzocca 1959).

${ }^{3}$ Nombre vernáculo que le asigna la población local a las entidades vegetales (Pochettino 2015), en este caso asignada por quién escribe el documento (Rosso 2013).

${ }^{4}$ Opuntia spp.

\section{${ }^{5}$ Cucumis melo.}

${ }^{6}$ El término "chacra" refiere a espacios destinados a explotaciones de carácter agrícola y "estancia" refiere a explotaciones ganaderas (Noli 1998).

${ }^{7}$ Refiere a la primera fructificación que ocurre al final de la primavera. Los higos negros corresponden a la segunda fructificación, al final del verano (Pochettino com. pers. 2020).

${ }^{8}$ Cucumis sativus. 